DOI: 10.12731/2658-4034-2020-1-64-75

\title{
МЕТОДОЛОГИЧЕСКИЙ АНАЛИЗ ДЕФИНИЦИЙ ПОНЯТИЙ «КОМПЕТЕНЦИЯ» И «РЕЗУЛЬТАТЫ ОБУЧЕНИЯ»
}

\author{
Шехмирзова А.М., Грибина Л.В.
}

ФГБОУ ВО «Адыгейский государственный университет»,

г. Майкоп, Республика Адыгея, Российская Федерация

В статье проводится методологический анализ дефиниций понятий «компетенция» и «результать обучения». Дается сущзностная характеристика рассматриваемых понятий в контексте требований новых стандартов. Подчеркивается значимость структурных компонентов образовательной программы в приобретении компетенций. Проводится сравнение понимания дефиниций с подходом в проекте Tuning.

Ключевые слова: компетенция; результаты обучения; компетентностный подход; компетентностная модель выпускника; образовательная программа; уровни формирования компетенщий; проект Tuning.

\section{METHODOLOGICAL ANALYSIS OF DEFINITIONS OF CONCEPTS "COMPETENCY" AND "LEARNING OUTCOMES"}

\section{Shekhmirzova A.M., Gribina L.V.}

Adyghe State University, Maikop, Adygea Republic, Russian Federation

The article provides a methodological analysis of the definitions of the concepts of «competence» and «learning outcomes». The essential 
characteristic of the concepts under consideration in the context of the requirements of the new standards is given. The importance of the structural components of the educational program in the acquisition of competencies is emphasized. The understanding of definitions is compared with the approach in the Tuning project.

Keywords: competency; learning outcomes; competency-based approach; competency-based model of a graduate; educational program; levels of formation of competencies; Tuning project.

Компетентностный подход, в соответствии с которым разработаны федеральные государственные образовательные стандарты высшего образования (ФГОС ВО), обуславливает отправной точкой в проектировании в вузе основной образовательной программы и каждого учебного модуля считать результаты обучения студентов.

Результаты обучения - это ожидаемые и измеряемые конкретные достижения студентов и выпускников, выраженные на языке знаний, умений, навыков, способностей, компетенций, которые описывают, что должен будет в состоянии делать/продемонстрировать студент/выпускник по завершении всей или части образовательной программы. Определить результаты обучения необходимо для того, чтобы цели обучения стали диагностичными, появилась возможность отслеживать процесс их достижения и своевременно вносить необходимые изменения в учебных процесс. Ожидаемые результаты обучения формулируются преподавателем с учетом мнений всех заинтересованных сторон (государства, работодателей, студентов). Компетенции приобретаются, осваиваются студентами. Вопрос оценивания сформированности компетенций является актуальной задачей. Сложность этой процедуры заключается в том, что любая компетенция является интегральной характеристикой личности. Результаты обучения - реперные точки, которые позволяют отслеживать и сопровождать этот процесс преподавателю.

В образовательной практике вуза целесообразно использовать комплексное понятие «результаты обучения», но важно понять, что эти результаты проектируются на основе понимания и анализа 
соответствующих компетенций и их взаимодействия. Поэтому на разных этапах образовательного процесса результатом обучения будут как сформированные элементы компетенций (определенные знания, умения, личностные качества, системы отношений, установки), так и сложные совокупности их взаимодействий, позволяющие судить уже об уровне сформированности компетенций, заложенных при целеполагании освоения модулей и образовательной программы в целом. Упорядочению (в определенной мере формализации) в понимании результатов обучения служит построение компетентностной модели выпускника, матрицы компетенций и разработка паспортов компетенций.

Результаты обучения определяются преподавателем, а компетенции приобретаются студентами и проявляются (а значит, могут быть оценены) только в процессе их деятельности. Компетенции формируются и развиваются не только через усвоение содержания образовательных программ, но и посредством используемых образовательных технологий, которые тоже должны проходить процедуру оценки [4].

Четко обозначенные, прописанные результаты обучения помогают студенту понять, что ожидается от него в процессе обучения, как и по каким критериям, будет оцениваться достигнутый результат. Вместе с тем, они концентрируют внимание и усилия преподавателей на достижении планируемого результата и его адекватной оценки и дают ясное представление потенциальным работодателям о реальных возможностях выпускников программы.

Особенность компетенции как результата обучения состоит в том, что в сравнении с другими результатами обучения она является интегрированным результатом и позволяет решать целый класс задач (в отличие от элемента функциональной грамотности). По мнению Е.Ю. Игнатьевой, компетенции существует в форме деятельности, а не информации о ней (в отличие от знания). К тому же они переносимы (связаны с целым классом предметов воздействия), совершенствуются не по пути автоматизации и превращения в навык, а по пути интеграции с другими компетенциями через осознание общей 
основы деятельности. Компетенции в процессе компетентностного образования наращивается компетенция, а сам способ действия включается в базу внутренних ресурсов (в отличие от умения), проявляется осознанно (в отличие от навыка) [4]. Так, результатами обучения на промежуточных этапах могут быть сформированные отдельные компоненты, составляющие соответствующую компетенцию. Важная проблема при этом - определение структуры компетенции (знания, умения, навыки, ценности/отношения к чему-либо и т.п.), потому что пока она не определена - непонятно, что формировать, что и как оценивать. Но в итоге эти компоненты обязательно должны интегрироваться в целостный конструкт - компетенцию, которую и должен будет демонстрировать студент, и для оценки которой требуется разработка специфических средств.

Компетентность как сложное интегральное личностное качество, которым обладает носитель компетенций, может проявляться и быть оценена только в действии и достаточно высокой мотивации достижения результата этого действия, является сложным, комплексным результатом обучения. А значит, оценка компетенций предполагает использование аутентичных способов оценивания (наблюдения, экспертиза продуктов профессиональной деятельности, защита портфолио) и разработки специальных оценочных средств (кейсов, включающих профессиональные задачи).

Компетенции могут определяться по-разному, но большинство моделей сейчас основывается на индикаторах поведения. Важно определить цели, для достижения которых будет использоваться разработанная модель компетенции [8]. Каждая компетенция - это набор родственных индикаторов поведения. Эти индикаторы объединяются в один или несколько блоков, в зависимости от смыслового объема компетенции.

Одним из значимых аспектов в методологии Tuning, представляющих для нас интерес в рамках исследования, стало различение между собой «результата обучения» и «компетенции», связанных с деятельностью участников образовательного процесса. Компетенции относятся к выпускнику, у которого они должны быть сформированы 
в результате освоения образовательной программы по направлению подготовки. Они выступают в качестве цели ОПОП, будучи выраженными на понятном для работодателей языке. Результаты обучения формулируются профессорско-преподавательским составом в виде ожидаемых и оцениваемых составляющих компетенций в соответствии с ФГОС ВО. Они выступают структурными элементами ОПОП ВО и измеряются на различных этапах процесса обучения.

Результаты обучения являются структурными элементами ОПОП (всего набора дисциплин (модулей), практик и т.п.). Компетенции формируются у обучающихся не в рамках одной дисциплины (модуля) или практики, а с применением всех составных структурных элементов ОПОП, включая образовательную среду вуза. Приобретение компетенций является циклическим интегративным процессом, в котором имеют значимость все структурные компоненты ОПОП, включая содержание образования, методы, формы обучения, образовательные технологии и др.

Результаты обучения и компетенции обеспечивают прозрачность системы европейского образования. В проекте результаты обучения рассматриваются в качестве ожидаемых показателей того, что выпускники должны знать и быть в состоянии выполнять по завершении освоения образовательной программы. Ожидаемые результаты обучения определяются преподавателями. Результаты процесса обучения определяются в терминах приобретаемых студентами компетенций.

Гармоничному соответствию результатов обучения с набором формируемых у выпускников компетенций, способствуют согласованные действия преподавательского сообщества и потенциальных работодателей.

Уровень освоения студентами компетенций можно оценить только в процессе их деятельности. Вопрос оценивания сформированности компетенций является актуальной задачей. Сложность этой процедуры связана с сущностной особенностью компетенций, являющихся интегральной характеристикой личности. Они формируются в процессе деятельности посредствам усвоения содержания 
образовательной программы с адекватным использованием образовательных технологий.

B проекте Tuning компетенции рассматриваются в виде динамичного сочетания знаний, навыков, понимания и способностей. Навыки часто могут использоваться в значении более узком, чем компетенции. Способности проявляются в виде динамической комбинации характеристик, обеспечивающих в совокупности компетентную деятельность.

В таком целостном контексте, компетенции проявляются в ситуации, когда студентом приводится в действие определенная способность, позволяющая выполнить поставленную задачу, уровень выполнения которой поддается оцениванию. При этом, невозможно в абсолютных величинах оценить наличие или отсутствие компетенции, поскольку владение ими происходит в различной степени, что позволяет говорить о возможности их формирования в ходе теоретического и практического обучения.

Как отмечает W. Hutmacher, значение компетенции удачно передается через выражения «знаю как» и «знаю что», позволяющее заключить, что именно применение и есть «компетенция в действии» [6]. С такой позицией согласуется и другой зарубежный исследователь К. Keеn, который определяет компетенции как способность человека управлять стандартными и непредвиденными ситуациями [7]. Для нашего исследования интерес представляет понимание в рамках проекта Tuning компетенции включающей знание и понимание, знание как действовать, знание как быть. Эти основные составляющие компетенции взяты за основу в исследованиях В.И. Бондаренко. Знание и понимание проявляется в теоретическом знании какой-либо академической области. Знание как действовать связано с практическим и оперативным их применением в конкретной ситуации. Знание как быть отражает ценностное восприятие личности и ее отношение к жизни, к окружающим в различных социальных контекстах. Приняв за основу такое понимание компетенции, исследователь заключает, что они представляют собой сочетание указанных характеристик позволяющих описать уровень овладения ими и сте- 
пень их реализации. Отсюда следует, что понятие «компетенции» содержит когнитивно-социальную, операционно-технологическую, мотивационно-поведенческую стороны [2].

Анализ Методических рекомендаций Минобрнауки РФ по разработке ОПОП и ДПО с учетом соответствующих Профстандартов (№ДЛ-1/05вн от 22.01. 2015 г.) показал, что в качестве основных составляющих результатов обучения по дисциплинам (модулям) рассматриваются знания, умения, навыки и формируемые компетенции. Отсюда следует, что измеряемыми составляющими элементами компетенций как результатов обучения выступают знания, умения, навыки, которыми должны овладеть обучающиеся и продемонстрировать после освоения составных элементов ОПОП. В этом случае, следует определиться с категориями для описания результатов обучения. С этой целью в дидактике, зачастую используются правильные активные глаголы, позволяющие успешно оценивать все ожидаемые результаты обучения. В ином случае, как отмечают многие зарубежные исследователи Adam, S. (Адам C.), Kennedy D. (Кеннеди Д.), Aine H. (Хайленд Э.), Ryan N. (Райан Н.), при несоответствии их своим назначениям, они признаются негодными. Для описания результатов обучения воспользуемся таксономией Блума, обеспечивающей готовой структурой и списком правильных активных глаголов. Очевидно, что в оригинальной работе Блума, составленный им материал списка глаголов не является исчерпывающим, но вместе с тем, он достаточно полный, чтобы взять его за основу для разных уровней высшего образования.

Основой разработки системы оценочных средств при текущем и промежуточном контроле и контрольно-измерительных материалов для государственной итоговой аттестации является описание планируемых уровней сформированности компетенций. Разработка ожидаемых (планируемых) уровней компетенций предполагает определение на этой основе этапов их формирования в процессе обучения через постепенное повышение сложности самостоятельно решаемых обучающимися задач. Выделение и описание уровней формирования (овладения) компетенций позволяет зафиксировать 
данный процесс от начала обучения до завершения освоения ОПОП (пороговый, средний, высокий).

Пороговый уровень сформированности компетенции соответствует характеристике квалификации (степени), получаемой выпускниками, освоившими образовательную программу по соответствующим уровням: бакалавриата, магистратуры, аспирантуры. Этот уровень обязателен для всех выпускников вуза для завершения освоения ОПОП ВО.

Средний уровень характеризует превышение характеристик минимальной выраженности овладения выпускником требуемой компетенцией.

Высокий уровень овладения компетенцией определяет ее максимально возможную выраженность у выпускника на основе самосовершенствования.

Уровни соответствуют усложняющимся ролевым функциям, выполняемые личностью в коллективной работе: член команды, поддержка членов команды, определение направленности команды и его предложение членам. Они позволяют установить единое понимание качественности осуществляемой деятельности, эффективности реализации компетенции на основе использования для ее описания общего языка. Как отмечают С. Уиддет и С. Холлифорд в своей книге «Руководство по компетенциям», хотя большинство компетенций характеризуется тремя уровнями, имеет место и одноуровневые, и двухуровневые, даже встречаются и четырехуровневые [7]. Это связано с выполняемыми личностью ролями и пониманием термина «компетенция». По мнению ученых, хотя зарубежные организации по-разному его трактуют, но в большинстве случаев компетенция представляется в виде определенной структуры. Зачастую, все сходятся в представлении в структуре основных элементов каждой компетенции, называемыми поведенческими индикаторами. При этом, поясняют авторы, компетенции без уровней охватывают ограниченный круг ролей, а с уровнями характеризуют различные роли. Несмотря на то, что исследование С. Уиддета и С. Холлифорда выполнено для сотрудников органи- 
заций, его результаты представляют интерес в рамках нашего исследования, в части учета Профстандартов при проектировании компетентностной модели выпускника вуза. Основу компетентностной модели выпускника, освоившего программу конкретного уровня высшего образования и направления подготовки составляют компетенции и результаты образования как главные целевыми установками в реализации ФГОС ВО.

Одной из существенно значимых аспектов в освоении и реализации компетентностного подхода в высшей школе является определение дескрипторов (описаний) компетенций выпускников, освоивших образовательные программы по направлениям подготовки в соответствии с ФГОС ВО. И здесь, по мнению многих российских ученых, следует иметь в виду, что речь должна идти не о национальных дескрипторах, а о соответствии российских и европейских требований, предъявляемых к подготовке выпускников для осуществления трудовой деятельности. При этом компетентностный подход становится основой создания единого механизма соотнесения академических степеней и квалификаций в результате освоения ОПОП различных стран. Для описания результатов (дескрипторов) следует выбрать простые и однозначные термины, понятные всем заинтересованным сторонам (студентам, преподавателям, работодателям) и внешним экспертам. Посредствам дескрипторов оценивается уровень сформированности компетенции по представленным компетентностно-ориентированным заданиям.

Значимость принятого нами в исследовании определения компетенции Лайлы и Сайны Спенсеров, заключается в заложенной ее измеримости на основе определенных критериев или стандартов. Спенсеры в качестве критериев рассматривают конкретные практические результаты сотрудников, к примеру, для продавцов - объемы продаж в долларах. В нашем исследовании эффективность выполнения необходимой профессиональной деятельности в соответствии с ФГОС ВО по направлению подготовки на основе овладения компетенциями в рамках освоения ОПОП определяется посредствам системы оценочных средств [3]. 
Таким образом, компетенции являются целью образовательной программы. Результаты обучения - оценкой достижения поставленных целей, то есть оценкой овладения компетенциями. Образовательный результат проявляется в том, что студент должен быть способен делать, то есть. сможет продемонстрировать по окончанию программы/модуля/дисциплины. Образовательные результаты должны быть измеряемы, именно они оцениваются в итоге. Компетенция относится к обучающемуся (выпускнику) и является целью образовательной программы, выраженной языком, понятным работодателю (как правило, компетенции выпускников определяются исходя из видов и задач профессиональной деятельности). Компетенции формируются в рамках различных элементов (единиц) образовательной программы и оцениваются на разных этапах обучения. Результаты обучения относятся к элементам (структурным единицам) образовательной программы (модулям, дисциплинам, практикам и др.) и формулируются преподавателями как ожидаемые и измеряемые «составляющие» компетенций: знания, практические умения, опыт деятельности, которые должен получить и уметь продемонстрировать обучающийся после освоения элемента образовательной программы.

Компетенции, как правило, не могут быть целиком сформированы одной дисциплиной или практикой, приобретение обучающимся компетенций является циклическим интегративным процессом, в котором кроме содержания образования важны также формы и технологии обучения и преподавания. Описание результатов обучения, как правило, характеризуется использованием активных глаголов (знать, понимать, уметь, иметь опыт деятельности в чем-либо). Результаты обучения могут относиться и к образовательной программе в целом («обобщенные результаты обучения»).

\section{Список литературы}

1. Игнатьева Е.Ю. Менеджмент знаний в системе менеджмента качества вуза: монография / Е.Ю. Игнатьева. Москва, 2007. 116 с.

2. Кузенков О.А. Алгоритм реформирования учебных программ по информационным технологиям в соответствии с технологией Тю- 
нинг / Электронное методическое пособие. Нижний Новгород. 2011. $69 \mathrm{c}$.

3. Спенсер-мл. Л.М., Спенсер С.М. Компетенции на работе. Модели максимальной эффективности работы. Пер. с англ. М: НІРРО, 2005. $384 \mathrm{c}$.

4. Средства оценивания результатов обучения студентов вуза: метод. рекомендации / Автор-сост. Е. Ю. Игнатьева; НовГУ им. Ярослава Мудрого. Великий Новгород, 2014. 62 с.

5. Hutmacher W. Key competencies for Europe // Report of the Symposium Berne, Switzerland 27-30 March, 1996. Council for Cultural Cooperation (CDCC) // Secondary Education for Europe Strasburg, 1997.

6. Keen K. Competence: What is it and how can it be developed? // Instructional Design: Implementation Issues / Eds. Education Center, 1992.

7. Whiddett S. A Practical guide to competencies [Text] / by S. Whiddett, S. Hollyford. London: Chartered Institute of Personnel and Development. 2006. (Русский перевод: Уиддетт С. Руководство по компетенциям / С. Уиддетт, С. Холлифорд. М.: Издательство ГИППО, 2008. 228 с.

\section{References}

1. Ignat'eva E.Yu. Menedzhment znaniy v sisteme menedzhmenta kachestva vuza: monografiya / E.Yu. Ignat'eva. Moskva, 2007. 116 s.

2. Kuzenkov O.A. Algoritm reformirovaniya uchebnykh programm po informatsionnym tekhnologiyam $\mathrm{v}$ sootvetstvii s tekhnologiey Tyuning / Elektronnoe metodicheskoe posobie. Nizhniy Novgorod. 2011. $69 \mathrm{~s}$.

3. Spenser-ml. L.M., Spenser S.M. Kompetentsii na rabote. Modeli maksimal'noy effektivnosti raboty. Per. s angl. M: HIPPO, 2005. $384 \mathrm{~s}$.

4. Sredstva otsenivaniya rezul'tatov obucheniya studentov vuza: metod. rekomendatsii / Avtor-cost. E. Yu. Ignat'eva; NovGU im. Yaroslava Mudrogo. Velikiy Novgorod, 2014. $62 \mathrm{~s}$. 
5. Hutmacher W. Key competencies for Europe // Report of the Symposium Berne, Switzerland 27-30 March, 1996. Council for Cultural Cooperation (CDCC) // Secondary Education for Europe Strasburg, 1997.

6. Keen K. Competence: What is it and how can it be developed? // Instructional Design: Implementation Issues / Eds. Education Center, 1992.

7. Whiddett S. A Practical guide to competencies [Text] / by S. Whiddett, S. Hollyford. London: Chartered Institute of Personnel and Development. 2006. (Russkiy perevod: Uiddett S. Rukovodstvo po kompetentsiyam / S. Uiddett, S. Kholliford. M.: Izdatel'stvo GIPPO, 2008. $228 \mathrm{~s}$. 